\title{
Intersections Between Grief and Trauma: Toward an Empirically Based Model for Treating Traumatic Grief Cheryl Regehr and Tamara Sussman
}

\author{
Version Publisher's \\ Citation Regehr, C., \& Sussman, T. (2004). Intersections Between Grief and \\ (published version) Trauma: Toward an Empirically Based Model for Treating Traumatic \\ Grief. Brief Treatment and Crisis Intervention, 4(3), 289-309. \\ http://dx.doi.org/10.1093/brief-treatment/mhh025
}

Copyright / License This work is licensed under the Creative Commons AttributionNonCommercial-NoDerivs 2.0 UK: England \& Wales License. To view a copy of this license, visit http://creativecommons.org/licenses/by-ncnd/2.0/uk/ or send a letter to Creative Commons, PO Box 1866, Mountain View, CA 94042, USA.

How to cite TSpace items

\begin{abstract}
Always cite the published version, so the author(s) will receive recognition through services that track citation counts, e.g. Scopus. If you need to cite the page number of the author manuscript from TSpace because you cannot access the published version, then cite the TSpace version in addition to the published version using the permanent URI (handle) found on the record page.
\end{abstract}

This article was made openly accessible by $U$ of $T$ Faculty. Please tell us how this access benefits you. Your story matters. 


\title{
Intersections Between Grief and Trauma: Toward an Empirically Based Model for Treating Traumatic Grief
}

\author{
Cheryl Regehr, PhD \\ Tamara Sussman, MSW
}

Two divergent areas of study have focused on the experiences of grief, i.e., bereavement, and on trauma and its aftermath. The grief literature has its foundations in psychodynamic and relational theories, and thus treatment modalities have focused on resolving relationship issues through reminiscence and developing a new sense of the relationship and of the self, independent of the lost loved one. The trauma literature, while having some psychodynamic roots, has been founded primarily on biological and cognitive formulations. Again, while many different treatments are discussed, cognitivebehavioral approaches based on cognitive restructuring and symptom management dominate the practice efficacy literature. But trauma and bereavement/loss are not mutually exclusive, and when a practitioner is faced with a client suffering from both, it is necessary to attempt to integrate these divergent theories and at times antithetical treatment approaches. This paper therefore seeks to address the issue of treatment efficacy in traumatic loss and develop guidelines for evidence-based approaches to practice. [Brief Treatment and Crisis Intervention 4:289-309 (2004)]

KEY WORDS: traumatic grief, traumatic loss, posttraumatic stress disorder, evidencebased practice.

Two parallel streams have emerged in the professional and academic literature - these regard grief, i.e., bereavement, loss of a loved one, and trauma. The grief literature has

From the Centre for Applied Social Research and Faculty of Social Work, University of Toronto.

Contact author: Cheryl Regehr, PhD, Centre for Applied Social Research, University of Toronto, 246 Bloor Street West, Toronto, Ontario, M5S 1A1. E-mail: cheryl.regehr@utoronto.ca.

DOI: 10.1093/brief-treatment/mhh025 focused on the process of mourning. The theory in this area has concentrated on relational dimensions and bereavement accompanying the experience of detaching from the deceased. Treatments recommended involve remembering the deceased, "working through" feelings, and attaining a new relationship with the missing loved one. By contrast, the trauma literature has examined responses to exposure to horrifying and life-threatening events. Theory and research in trauma have long

Brief Treatment and Crisis Intervention Vol. 4 No. 3, (c) Oxford University Press 2004; all rights reserved. 
considered both the psychological and physiological dimensions of terror and its aftermath. Distressing memories and physiological reactions are viewed as symptoms of a disorder. Treatment is aimed primarily at symptom management and eradicating intrusive images of the traumatic event. Yet, trauma and grief are often not mutually exclusive. People survive accidents that their loved ones do not. Family members are murdered. Children die suddenly. Depending on the suddenness and violence and the sense of justice associated with the loss, as well as the nature of the relationship between the deceased person and the survivor, people may suffer trauma and grief simultaneously. This requires that we develop and test intervention strategies that deal with these complex situations.

Despite the proliferation of theoretical and clinical literature in the area of grief studies, the empirical basis for theoretical constructs and resulting treatment approaches in the area of grief work is quite weak (Jordan \& Neimeyer, 2003). In the area of trauma, outcome studies do point to the efficacy of some approaches, particularly those with cognitive-behavioral foundations (Follette, Ruzek, \& Abueg, 1998; Harvey, Bryant, \& Tarrier, 2003; Rothbaum \& Foa, 1996). However, there is evidence that the application of certain approaches with clients who possess certain vulnerabilities or characteristics may in fact be iatrogenic (Regehr, 2001). Traumatic grief is an emerging construct, and few treatment approaches specifically address its issues, yet a growing body of evidence exists upon close examination of inclusion criteria for grief and trauma intervention studies. This research literature can form the foundation for an evidence-based approach to clinical practice with individuals suffering from traumatic grief.

Evidence-based practice is defined as the conscientious, explicit, and judicious use of the best available scientific evidence in profes- sional decision making (Sackett, Richardson, Rosenberg, \& Haynes, 1997). More simply defined, it is the use of treatments for which there is sufficiently persuasive evidence to support their effectiveness in attaining the desired outcomes (Rosen, Proctor, \& Staudt, 2003) for the particular problem and for clients with the characteristics of those presently being served (Roberts \& Yeager, 2004). This paper examines the intersection between trauma and grief/bereavement and attempts to determine empirically based approaches for treatment interventions in the event of traumatic loss. Considering the intensity of these tragic events and the depths of despair that may be experienced by individuals who encounter traumatic loss, it is imperative that mental health professionals respond with approaches that do in fact assist to relieve suffering and do not carry the risk of elevating symptoms.

\section{Foundations of Grief Theory}

Throughout the past century, grief work has been the major theoretical construct to explain how people cope with bereavement. Due to the fact that virtually all humans can be expected to experience significant loss at some time in their lives, grief is viewed as a normal, albeit distressing, process. High levels of emotion are experienced but are viewed as having a clearly defined goal, that is, helping the bereaved abandon the commitment to the relationship with the deceased (Freud, 1917). Movement toward resolution is conceptualized to occur in stages or phases during which individuals complete a series of mourning tasks. While the number of stages or tasks one passes through differs in the various conceptual modes, commonalities exist. In general, the first stage is described as acute grief, which is characterized by numbness, frequent yearning for the deceased, and denial of the permanence 
or reality of the loss. Although bereavement theorists are hesitant to provide timelines for normal grief patterns, this stage is thought to typically last a number of weeks, generally 6 to 8 (Humphrey \& Zimpfer, 1996; Worden, 1991). Once the permanency of the loss becomes a perceptual reality, the bereaved typically is thought to experience an extended period of disorganization and despair which can last several months (Shuchter \& Zisook, 1993). Finally, as the intensity of loss-related emotion begins to subside, the bereaved individual enters a phase of reorganization in which he or she must learn to function in an environment without the deceased and come to a new sense of the lost relationship (Bowlby, 1980; Parkes, 1996; Worden, 1991). This stage is still accompanied by elevated emotions; however, the frequency of yearning and crying and the centrality of the loss in the bereaved individual's life begin to diminish. According to many grief theorists, the process of normal grieving is expected to last between 1 and 2 years and varies depending upon the nature of the relationship between the deceased and the bereaved and the circumstances surrounding the death (Humphrey \& Zimpfer, 1996; Worden, 1991).

A somewhat different interpretation of the process of grief is proposed by Stroebe and Schut (1999), who put forth a dualistic model of bereavement which suggests that grieving is a dynamic process that reflects both the realization of the loss and the continued fight against the reality of the loss. These theorists propose that bereaved people have a tendency to oscillate between confronting and avoiding loss at every stage of the bereavement process. Accordingly, people engage in both loss orientation, which concentrates on dealing with some aspects of the loss (e.g., yearning for the deceased, looking at old photos, crying about the death), and restoration orientation, which concentrates on life changes (e.g., how to deal with social loneliness). Unlike stage theorists, Stroebe and Schut do not propose that one orientation necessarily proceeds another, but rather suggest that a balance between both is normal and necessary during the course of bereavement. What remains unclear is the ideal balance between confrontation and avoidance.

These conceptual models for understanding bereavement have contributed to a view that people experiencing grief subsequent to loss must confront and work through their reactions. This notion that one has to process grief can be traced back to Freud (1917), who described the "work of mourning" as a process wherein the bereaved reminisces and emotionally experiences the memories and significance of the deceased, as a step toward letting go of involvement with him or her. Like Freud, Stroebe (1992) defined working through as "a cognitive process of confronting a loss, of going over the events before and at the time of the death, of focusing on memories and working towards detachment from the deceased" (p. 20). These definitions have been maintained by others (Rando, 1992; Sanders, 1993; Worden, 1991). There are two assumptions articulated in this conceptualization. One is that individuals must express their emotions, particularly negative ones, in order to resolve their grief; and the second is that this highly painful and emotional process will help the bereaved to detach from the deceased and achieve resolution. The first assumption has guided most clinical grief interventions: The primary goal for practitioners is often to help individuals work through the process of grief by expressing both positive and negative emotions directed toward themselves, the deceased, and others. Failure to express these highly charged emotions is assumed to put individuals at risk of complicated grief, specifically delayed grief reactions.

Thus, clinical theorists consistently promote the need to confront grief-related emotions as 
a means of achieving "grief resolution." Clinicians offering grief therapy to individuals evidencing both normal and pathological patterns of bereavement are encouraged to facilitate the expression of grief-related emotion by asking the bereaved to identify and experience feelings such as what they do and don't miss about the deceased and what negative feelings they have toward the deceased (Bowlby, 1980; Humphrey \& Zimpfer, 1996; Worden, 1991). Expressing both positive and negative emotions regarding the deceased is seen as important in grief resolution, as this phase requires the integration of a balanced and realistic memory of the deceased rather than an idealized or completely negative one (Humphrey \& Zimpfer, 1996; Worden, 1991). Further, guided by these stages of grief, counselors are advised to help individuals express their numbness and yearning so that the reality of the loss can be actualized; to identify and work through their despair, including their feelings regarding the lost relationship, so that the intensity and frequency of grief-related emotions can dissipate; and finally to focus on the external world so that lost roles and selfconcepts can be re-formed. Although stages/ phases are not necessarily meant to be linear, it is a clear assumption that one cannot experience the stage of reorganization without having verbalized and worked through the emotions identified in the first stages of grief.

\section{Foundations of Trauma Theory}

The experience of psychological trauma in response to exposure to horrific events is a theme that can be found in the earliest of literature. Achilles in Homer's Iliad and Hotspur in Shakespeare's Henry the IV are frequently cited as excellent portrayals of what we now understand to be traumatic stress reactions secondary to involvement in combat. Psychia- trist Pierre Janet is quoted as writing in 1919: "All famous moralists of olden days drew attention to the ways in which certain happenings would leave indelible and distressing memories - memories to which the sufferer was continually returning, and by which he was tormented by day and by night" (quoted in van der Kolk \& van der Hart, 1989, p. 1530). In the late 1800s and early 1900s many physicians began describing reactions to traumatic events, including both physical responses (such as "irritable heart" [DaCosta, 1871; Oppenheimer \& Rothschild, 1918]; posttraumatic spinal cord injuries due to nervous shock and without apparent lesions [Page, 1885]; and "neurasthenia," a physical disorder associated with fear [Mott, 1918]) and psychological reactions such as "war neurosis" (MacKenzie, 1916) and "shell shock" (Southward, 1919).

Two main theories emerged out of this literature. The first was proposed by Freud, who suggested the concept of "anxiety neurosis," or "hysteria," in which a horrific psychological event leads to physical consequences (Turnbull, 1998). The second suggested that the impact of physical forces on the central nervous system experienced during a traumatic event such as a rail disaster or combat resulted in a temporary neurological dysfunction, which in turn leads to symptoms (Turnbull, 1998). However, this interest in the effects of psychological trauma on individuals subsided after the end of the First World War and did not resurface until the mid-1970s. At that time, interest in the effects of war on Vietnam veterans emerged, resulting in the concept of "posttraumatic stress," and interest in the effects of rape on victims emerged, resulting in the concept of "rape trauma syndrome" (Burgess \& Holstrum, 1974). Together, the pressures arising from the needs of these two highly divergent groups of sufferers resulted in official recognition of posttraumatic stress disorder (PTSD) in the Diagnostic and Statistical 
Manual of Mental Disorders (DSM) (American Psychiatric Association, 1980).

One aspect of trauma response is viewed as neurophysiological. As a result of exposure to an experience of fear or danger, individuals undergo neurophysiological changes that enhance the capability for fight or flight. These biological responses generally return to normal levels within a period of hours. In individuals suffering from posttraumatic stress, however, several biological alterations remain, including an enhanced startle response that does not habituate, increased activation of the amygdala, alterations in the hypothalamus, and decreased cortisol levels (van der Kolk, 1997; Yehuda, 1998; Yehuda, 2002). Thus, autonomic hyperarousal mechanisms related to the event continually recur and are exacerbated by traumatic memories and images. The sufferers thus find themselves alternating between states of relative calm and states of intense anxiety, agitation, and anger and hypervigilance (Roberts, 2002). In part, the neurophysiological influence is evidenced by the disorganization in trauma memory and the difficulty in producing a coherent narrative (Brewin, 2001). As individuals attempt to reconstruct events, they discover gaps and experience spontaneous flashbacks, which they attempt to control by manipulating the probability of their being triggered by stimuli (Brewin, 2001). Thus, in order to cope with the symptoms, the individual frequently attempts to avoid exposure to stimuli that are reminiscent of the event or to shut out memories of the event. From this perspective, treatment focuses on controlling stimuli and on symptom management.

What is problematic about the biological formulation, however, is that there is considerable evidence that not all people will have traumatic stress reactions to a catastrophic event. Several studies have shown that $50 \%$ to $80 \%$ of men and women experience potential traumatic events but that the majority do not develop PTSD, which requires that the symptoms continue for more than 1 month. For instance, a nationally representative study of 512 Israelis who had been directly exposed to a terrorist attack and 191 who had family members exposed demonstrated that while $76.7 \%$ had at least one symptom of traumatic stress, only $9.4 \%$ met the criteria for PTSD (Bleich, Gelkopf, \& Solomon, 2003). In this study, the majority of people expressed optimism and self-efficacy regarding their ability to function in a terrorist attack. Similarly, a study of Latino primary care patients in the United States revealed that of those who had experienced political violence in their homeland, 18\% met the criteria for PTSD (Eisenman, Gelberg, Liu, \& Shapiro, 2003). The lifetime prevalence of PTSD in the general population of the United States is reported to be $5 \%$ for men and $10 \%$ for women (Kessler, Sonnega, Bromet, Hughes, \& Nelson, 1995). This is not to say that individuals are unaffected by the events, but rather that they have symptoms of distress that for the most part subside within a relatively short period of time. These findings provoked Shalev (2002) to suggest that traumatic events may be more appropriately called potentially traumatizing events. Thus, the evidence is that most people are resilient and adaptive following a traumatizing event.

It has been suggested that the ability to contain disruption caused by trauma within reasonable boundaries is associated with a cluster of personal attributes, including mastery, control, flexibility, and optimism. This understanding of trauma response is primarily cognitive in nature. That is, a traumatic event violates assumptions that individuals hold about the world, such as, "If I drive safely, I will not get into a horrific accident." As a result of this disjuncture between an individual's view of the world and the event that has occurred, his or her normal adaptive mechanisms fail to be activated. Sensory images of the 
event are stored in active memory, where they are repeatedly experienced. These intrusive thoughts and images give rise to feelings of anxiety, guilt, and fear (Horowitz, 1976). From this perspective, an individual attempts to cope with the traumatic imagery by (1) failing to be sensitive to the discrepant information, (2) interpreting the meaning of the information in a way that is consistent with current beliefs, or (3) altering existing beliefs to match the experience (McCann, Sakheim, \& Abrahamson, 1988). Those individuals who are able to maintain a sense of control and optimism regarding the outcome of the event are thus expected to fare better. Treatment therefore is aimed not only at controlling symptoms, but in addition at cognitive restructuring of the meaning of the event and the degree of control that an individual has over the outcome of the event.

These formulations, however, ignore other factors that influence the individual and his or her response to trauma, such as whether the origin of the event is attributable to human intention or to natural causes (Briere \& Elliott, 2000) and the secondary losses or stressors associated with the event (Brewin, Andrews, \& Valentine, 2000; Green, 2000; Hobfoll, 2001). In addition, the degree of support in the environment is important, including the individual's personal network and the community response to the event.

\section{Intersections Between Grief and Trauma}

While grief theory and trauma theory have differing perspectives on the etiology and outcome of tragic events, clearly grief (bereavement, loss) and trauma are not mutually exclusive. Lindemann (1944), for instance, conceptualized crisis and loss while following the experiences of the survivors of a 1942 fire in the Coconut Grove nightclub in Boston, in which close to 500 people died. Lindemann observed and documented the reactions of the survivors, which included somatic responses, behavioral changes, and emotional responses such as grief and guilt. In describing the process of their recovery, he noted the importance of grieving, adapting to the loss, and developing new relationships. Undoubtedly these individuals experienced the trauma of near-death and witnessing death as well as grief related to the loss of loved ones. Yet, despite the overlap between trauma and grief (see Figure 1), the two experiences are conceptualized as distinct by some theorists and indistinguishable by others. Raphael (1997) has considered the differences between the experiences of trauma and grief. For instance, she notes that although both have intrusive thoughts or memories, traumatic memories focus on specific negative or horrifying aspects of the event, while grief memories focus on the lost person and can be either positive or negative in nature. Anxiety in traumatized individuals tends to be related to threat and fear rather than separation, as it is in bereaved individuals. Further, while traumatized people tend to be avoidant and socially withdrawn, bereaved people often seek out reminders and social support. Unresolved trauma reactions are seen to lead to chronic PTSD, while unresolved grief issues are more associated with depression (American Psychiatric Association, 2002). Conversely, Brom and Kleber (2000) suggest that "there is no need to see the response to the loss of a close person as essentially different than the response to other traumatic events" (p. 48). In the case of a natural death, the survivor may be preoccupied with images of the deceased and feel longing, sadness, and depression. If the bereaved witnessed a death by force or calamity, the images may be more violent and the emotional response one of rage or helplessness. Nevertheless, in the researchers' view, the altered content does not represent a distinct entity. 


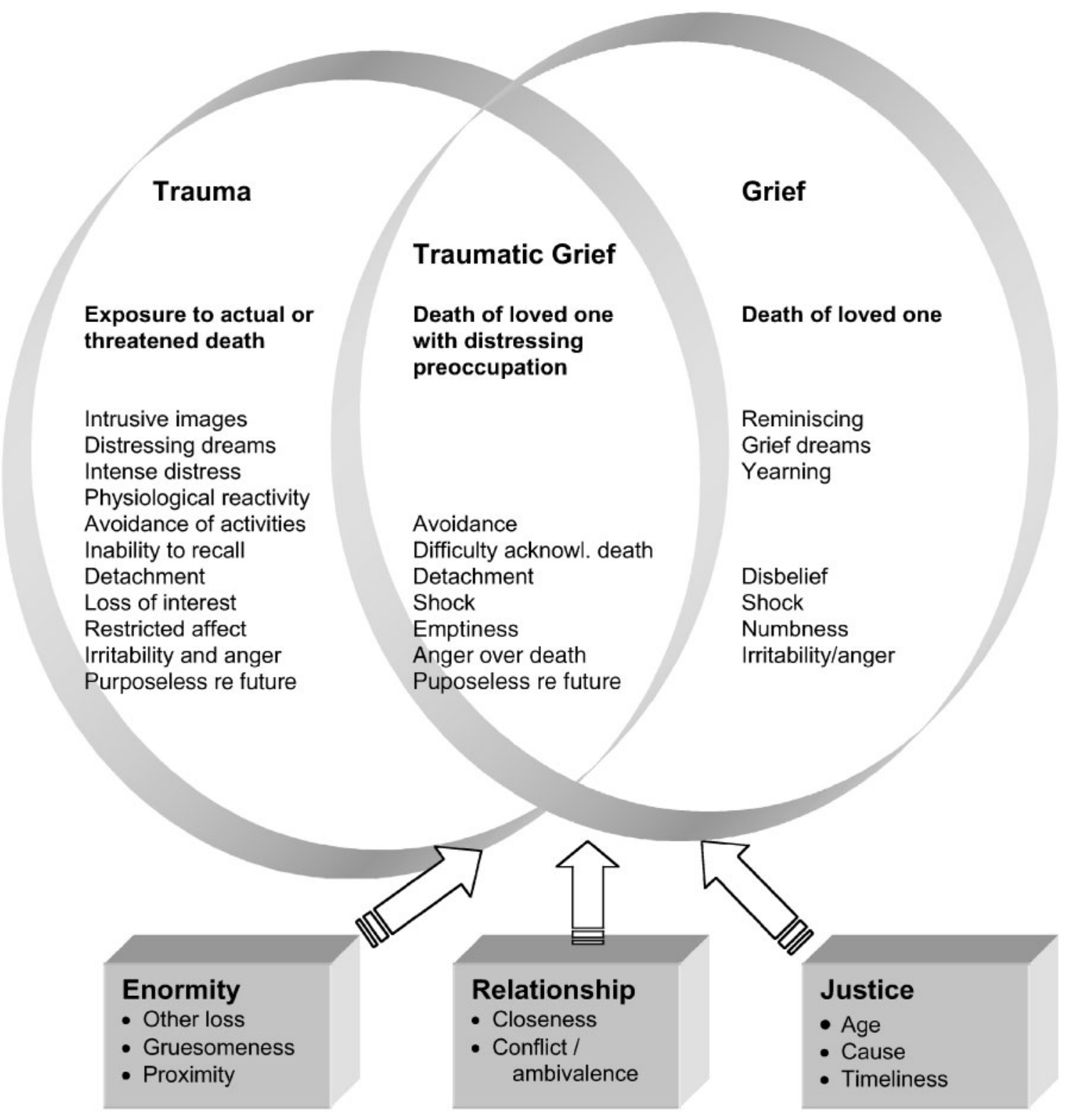

\section{FIGURE 1}

The relationship between trauma and grief.

Recent theorists and researchers have discussed the conceptual links between grief and trauma (Green, 2000; Pfefferbaum et al., 2001; Stroebe, Schut, \& Finkenauer, 2001). Others are attempting to move beyond the distinctions between grief and trauma and develop criteria for a new category, that of traumatic grief. Prigerson, Shear, and colleagues (1999) have proposed consensus criteria for traumatic grief based on PTSD criteria in the DSM, fourth edition, revised (American Psychiatric Association, 2002). In Prigerson et al.'s model, Criterion A requires the death of a significant other and a response to that death involving intrusive, distressing preoccupation with the deceased person, such as yearning, longing, or searching. Criterion B requires a combination of the following symptoms: efforts to avoid 
reminders of the deceased; feelings of purposelessness and futility about the future; a sense of numbness or detachment resulting from the loss; feeling shocked, stunned, or dazed by the loss; difficulty acknowledging the loss; feeling that life is empty and unfulfilling without the deceased; a fragmented sense of trust, security, and control; and anger over the loss. Thus, while the symptoms parallel traumatic stress, there is no discussion about the nature of the death as a specific criterion. Horowitz and colleagues (1997) have similarly proposed a new diagnostic category of complicated grief disorder, which includes such symptoms as intense intrusive thoughts, severe pangs of emotion, denial of implications of the loss to self, feelings of exceptional aloneness and emptiness, excessive avoidance of tasks reminiscent of the deceased, sleep disturbances, and neglect of necessary adaptive activities at work or at home- - lasting more than 1 year postbereavement. Again, the nature of the loss is not specified. Based on conceptualizations of traumatic grief, Boelen, van den Bout, and de Keijser (2003) have developed the Inventory of Traumatic Grief, which differentiates between traumatic grief and bereavement-related depression and anxiety.

Empirical evidence confirms that when trauma and grief occur together, subsequent reactions are more prolonged and distressing. Traumatic grief has been associated with a fivefold increase in the likelihood of suicidal ideation in young adults (Prigerson, Bridge, et al., 1999). When compared with those who experienced a traumatic event in the form of an assault, a sample of young women who had experienced traumatic loss had higher rates of intrusive symptoms, reexperiencing symptoms, and impaired school performance (Green et al., 2001). It is important to attempt to distinguish which factors differentiate grief over loss from traumatic grief. Stroebe, Schut, and Finkenauer (2001) suggest that traumatic grief can be distinguished from grief/loss responses based on the enormity of the event and from trauma responses based on the fact that the enormity includes a consideration of the intensity of the relationship with the deceased. Green and colleagues, in studying the survivors of the Beverly Hills Supper Club Fire, which killed 165 people (Green, Grace, \& Gleser, 1985), and the survivors of a dam collapse at Buffalo Creek (Gleser, Green, \& Winget, 1981), found that the closeness of the relationship with people lost in the disaster predicted similar or higher levels of distress as that of personal life threat. Other researchers suggest that the quality of the bond, ambivalence related to the relationship, or unhealthy attachments are important predictors (Field, Nichols, Holen, \& Horowitz, 1999; Worden, 1991). Similarly, when death is violent, such as due to accident or homicide, bereavement has been found to be more complicated in terms of prolonged symptoms of PTSD and depression (Kaltman \& Bonanno, 2003; Thompson, Norris, \& Ruback, 1998). Factors which contribute to traumatic grief in individuals who have lost a loved one to murder include not only shock and disbelief, but also a sense of injustice regarding community and legal response to the event (Armour, 2002; Rock, 1998). In addition to the cause of death, factors related to perceptions of justice include the age of the deceased, whether or not the death was expected, and the co-occurrence of other losses or stressors. Death of a child is uniformly associated with prolonged and complicated grief in parents (Finkbeiner, 1996; Weiss, 2001). In the case of death during disaster, other concurrent losses and disruptions add to the experiences of loss and trauma (Najarian, Goenjian, Pelcovitz, Mandel, \& Najarian, 2001; Norris, Friedman, \& Watson, 2002).

Thus, there is a movement to consider traumatic grief as a distinct entity that encompasses elements of bereavement and trauma, yet acknowledges that in combination these 
experiences result in higher levels of distress. This requires that we consider what treatment approaches might be of greatest benefit to those suffering from traumatic grief, as approaches to trauma treatment and grief treatment are highly divergent from one another.

\section{Empirical Evidence for Bereavement Interventions}

As stated above, the central theme of grief treatment is the notion of working through the mourning through reminiscing and emotionally experiencing memories of the deceased. At best, however, the efficacy of working through the emotions of grief appears equivocal in empirical research. Some studies have demonstrated that the expression of grief-related emotion during the initial stage of bereavement does lead to lower symptomatology over time. For example, Stroebe and Stroebe (1993) found that widowers who confronted their grief during the first 4 to 7 months following their loss suffered fewer depressive and somatic symptoms after 2 years. Further, Lepore and colleagues (1996) found that parents who had lost a child to sudden infant death syndrome and who focused on disclosure of feelings showed lower depression rates than those who did not, if their social environment was perceived as supportive of such disclosures. Conversely, however, prospective longitudinal studies have found no associations between negative emotional expression during the first 6 months of a loss and grief symptoms 5 years later, suggesting that failure to do "grief work" in the initial stages of bereavement does not necessarily lead to prolonged or delayed grief (Bonanno \& Field, 2001; Middleton, Burnett, Raphael, \& Martinek, 1996). Other prospective studies confirm that grief work is no more efficacious than avoidant strategies (Archer, 1999; Stroebe \& Stroebe, 1991).
There are four recent reviews of the bereavement intervention literature (Kato \& Mann, 1999; Litterer Allumbaugh \& Hoyt, 1999; Neimeyer, 2000; Schut, Stroebe, van den Bout, \& Terheggen, 2001). Kato and Mann (1999) conducted a qualitative and quantitative review of 13 randomized controlled bereavement studies, separating their analyses by intervention type (individual, family, or group). According to their review, the 3 studies offering an individual intervention for grief found small but inconsistent improvement in the physical health of the bereaved as measured by perceived health (Gerber, Wiener, Battin, \& Arkin, 1975; Raphael, 1977; Vachon, Lyall, Rogers, Freedman-Letofsky, \& Freeman, 1980). Vachon and colleagues (1980) demonstrated improvement in perceived health on the general health questionnaire (GHQ) for bereaved women who were paired with other widows trained in supportive counseling and whose grief was considered resolved. The widows who were particularly distressed at the onset benefited the most from the intervention. Kato and Mann (1999) caution, however, that the difference between groups on perceived level of social support prior to the intervention may have accounted for some of the differences noted in the study. Gerber and colleagues (1975) and Raphael (1977) studied interventions for acutely bereaved individuals receiving individual counseling from a professional counselor. Participants in the Gerber et al. study received a 6-month intervention which focused on both emotional resolution and practical advice. While the control group had more visits to their doctor immediately after the intervention, there was no difference upon long-term followup 8-15 months after the loss. Further, individuals participating in the intervention did not differ from nontreatment controls in their medication use and reported health during, immediately after, or 6 months after treatment. In the Raphael study, widows 
receiving a 3-month intervention were considered at high risk because they either had an unsupportive social network, the death had been untimely or unexpected, they had had a highly ambivalent marital relationship, or they had a concurrent life crisis. Individuals receiving the intervention were offered ego support and encouraged to express their grief and to work through their ambivalent relationship with the deceased. Using the Goldberg $\mathrm{GHQ}$, individuals in the intervention group were found to have improved more than controls on measures of anxious symptoms, depressive symptoms, and somatic symptoms.

Less efficacious findings were reported by Kato and Mann (1999) on the eight group interventions they reviewed. According to these reviewers, six or eight group interventions showed no beneficial effects (Barrett, 1978; Duran, 1987; Sabatini, 1988; Tudiver, Hilditch, Permaul, \& McKendree, 1992; Walls \& Meyers, 1985; Weidaw, 1987). The predominant intervention used in these group studies was a combination of lectures about the grieving process and an open discussion of grief-related emotions. All of these groups were led by professionals in psychology, nursing, or mental health, with the exception of Tudiver and colleagues (1992), which was a self-help model led by volunteer widows. While study participants in the intervention conditions in all groups did improve over time, so did individuals in the control condition. The study by Constantino (1988), one of the two group interventions judged to be effective by Kato and Mann (1999), consisted of bereaved widows long after the loss and may therefore more accurately be measuring individuals experiencing more chronic grief.

Kato and Mann's (1999) meta-analysis of the 11 studies found a very small positive effect for physical health, and no effect for depression or other stress-related outcomes. Their separation of group and individual interventions reveals that much of this effect is accounted for by bereavement interventions offered to individuals rather than in the form of support groups. Further, those individual interventions which were found to be effective were either offered to individuals more highly distressed (Brom, Kleber, \& Defares, 1989; Gerber et al., 1975; Raphael, 1977) or were most effective for those individuals starting the intervention with higher levels of distress (Vachon et al., 1980).

Litterer Allumbaugh and Hoyt (1999) focused on client factors associated with better or poorer outcomes. They found that younger individuals (25-35 years) and the elderly (6685) experienced less helpfulness from interventions. Further, spouses seemed to benefit less from grief-related interventions than did nonspouses. Finally, individuals who voluntarily sought treatment benefited more from interventions than did individuals who responded to study-recruitment strategies. Contrary to expectations, the researchers did not find a difference in outcomes for complicated bereavement and normal bereavement; however, it was suggested that this was due to inconsistent definitions of complicated bereavement between studies.

Noting that Kato and Mann excluded a number of studies in their review, Neimeyer (2000) conducted a meta-analysis of 23 randomized controlled studies offering individual, family, or group interventions to individuals who were mourning the death of a loved one. Like Kato and Mann (1999), he concluded that the overall effect upon all individuals seeking counseling following loss was positive but very small. According to his analysis, the average person seeking counseling for bereavement was better off than only $55 \%$ of bereaved persons receiving no treatment at all. This outcome did not appear to be related to treatment type (individual, family, or group) or treatment approach; however, most studies in his review shared the common theme of facilitating the 
working through highlighted in the theoretical literature. The author did find that individuals who were seeking counseling for normal grief experienced no positive effect, while those seeking counseling for more complicated grief (violent nature of the death, chronic bereavement) showed a reliable positive effect.

Schut, Stroebe, van den Bout, and Terheggen (2001) conducted a review of the bereavement literature separating studies examining interventions offered to all bereaved individuals (to prevent grief-related complications) from studies examining interventions aimed at individuals at higher risk for bereavement-related complications and studies examining interventions aimed at individuals experiencing some form of complicated grief. These authors concluded that (1) people with otherwise normal patterns of grief do not seem to benefit from bereavement interventions in the long term, especially if they are grieving the loss of a spouse, and (2) people showing signs of more complicated grief seem to benefit the most from interventions. They caution, however, that studies looking at individuals with complicated grief offer interventions much later on in the grief process than other studies and that the individuals participating in the intervention studies tend to be help seekers (i.e., looking for an intervention) rather than study recruits (i.e., accepting an intervention by agreeing to participate in a study).

Two recent studies compared the effects of two group interventions for individuals deemed to have elevated levels of grief-related symptoms 3 months following the loss of a loved one (Ogrodniczuk, Piper, McCallum, Joyce, \& Rosie, 2002; Piper, McCallum, Joyce, Rosie, \& Ogrodniczuk, 2001). These researchers randomly assigned individuals to either a supportive treatment or an interpretive treatment. The researchers found that individuals with more secure attachments to the deceased
(Ogrodniczuk et al., 2002) and more psychological mindedness (Piper et al., 2001) did better in both treatments. However, individuals with higher-quality relations with all attachment figures (i.e., better relational capacity) did better in the interpretive group, and individuals with lower-quality relations did better in the supportive group.

In summary, when the short-term efficacy of bereavement interventions is studied, results are somewhat positive for individuals experiencing normal patterns of grief. However, examining results over time reveals that individuals who are experiencing higher than average levels of distress benefit from a variety of interventions offered individually, while individuals with normal patterns of grief seem to experience temporary gains only. Further, even when individuals are deemed "at risk" for grief-related complications (i.e., they had ambivalent relationships with the deceased, were experiencing concurrent life crises, or the deceased died suddenly or violently), they do not necessarily benefit from bereavement interventions unless they are actually experiencing higher levels of distress. Treatment for individuals experiencing loss in tragic or traumatic circumstances will be discussed further in the section on interventions for traumatic loss.

\section{Summary of Grief Treatment Research}

- Limited evidence supports the view that expression of grief leads to resolution.

- Those with normal grieving patterns do not seem to benefit from intervention, while those with complex grief seem to benefit from individual treatment.

- Those with ambivalent relations with the deceased may benefit from relationally focused treatment. 
- Those with lower relational capacity may benefit more from therapy aimed at providing immediate support and problem solving rather than interpretation and conflict exploration.

\section{Empirical Evidence for Trauma Interventions}

Similar to the process of evaluating grief interventions, one of the issues in evaluating posttraumatic stress interventions is the degree to which symptoms spontaneously remit. For instance, Rothbaum, Foa, Riggs, Murdock, and Walsh (1992) reported that while $94 \%$ of the 95 rape victims in their study met the criteria for PTSD at 1 week postrape, this reduced to $47 \%$ at 94 days postrape. It has been suggested that once the 3-month marker is reached or surpassed, symptoms of PTSD become relatively persistent (Cohen \& Roth, 1987; Kilpatrick, Resick, \& Veronen, 1981). Nevertheless, Tarrier, Sommerfield, Reynolds, and Pilgrim (1999) discovered that $11 \%$ of patients with chronic PTSD improved with clinical assessment and self-monitoring to the extent that they no longer qualified for a diagnosis. Thus, while there are hundreds of original reports describing the effectiveness of treatments for individuals who have been exposed to traumatic events, the vast majority are not empirically based studies (Solomon \& Johnson, 2002). Yet, the natural diminution of symptoms of PTSD requires that controlled studies be considered when discussing efficacy.

While many excellent reviews and metaanalyses exist of the research related to treatment efficacy for traumatized individuals, it is generally acknowledged that only cognitive-behavioral and psychopharmacological methods have been subject to rigorous evaluation with controlled trials (Ehlers \& Clark, 2003; Hembree \& Foa, 2003; Katz, Pellegrino, Pandya,
Ng, \& DeLisis, 2002; Solomon \& Johnson, 2002). Pharmacological treatment for trauma sufferers has yielded positive results in assisting with symptom management. In particular, selective serotonin reuptake inhibitors have shown positive results (Albucher \& Liberzon, 2002), and mood stabilizers have shown promise (Albucher \& Liberzon, 2002; Katz et al., 2002), as have beta-blockers (Katz et al., 2002).

Follette, Ruzek, and Abueg (1998), Harvey, Bryant, and Tarrier (2003), and Rothbaum and Foa (1996) provide extensive overviews of the effectiveness of cognitive-behavioral approaches for posttraumatic stress disorder. They conclude that cognitive-behavioral therapy (CBT) is effective in reducing the severity of PTSD symptoms in individuals who have experienced a wide range of traumatic events and in those who suffer from both acute and chronic symptoms. CBT has been demonstrated to have superior effects over supportive treatment in the treatment of PTSD in a number of controlled studies (Bryant, Sackville, Dang, Moulds, \& Guthrie, 1999). Cognitive therapies come in a variety of forms. Exposure therapy is based on the notion that the common strategy of avoiding trauma-related memories and cues interferes with emotional processing of the event by reinforcing erroneous cognitions and fears. During imaginal and in vivo exposure and recounting the event, individuals are assisted to manage the resulting anxiety and allow distress to habituate. Stress inoculation training, based on social learning theory, teaches individuals to manage fear and anxiety through cognitivebehavioral techniques. Cognitive therapy assists individuals to identify trauma-related dysfunctional beliefs that influence response to stimuli and subsequent physiological and psychological distress. Some studies have provided evidence that exposure therapy in combination with stress inoculation training or cognitive therapy yields the most positive results (Hembree \& Foa, 2003); others have 
provided evidence that inoculation does not necessarily enhance other cognitive methods, which, of themselves, are equally effective (Harvey, Bryant, \& Tarrier, 2003; Tarrier, Pilgrim, et al., 1999). It is important to note that exposure methods are more selective in the criteria for inclusion, and it is suggested that this model of treatment be used only when a sound therapeutic alliance has been formed and a thorough assessment completed (Calhoun \& Atkeson, 1991). Individuals in this type of treatment group should be assessed to have the capacity to tolerate high anxiety arousal and to have no active suicidal ideation, comorbid substance abuse, or, most importantly, current life crises (Foy et al., 2000). Thus, if they are equally effective, CBT methods without exposure may yield a lower risk of iatrogenic effects.

Group treatment methods are less clear-cut. One form of group treatment is the singlesession debriefing, which has been the subject of much controversy regarding efficacy. In general, however, findings suggest that professionals exposed to trauma in the context of their job subjectively find single-session debriefings to be helpful and supportive, although such sessions do not relieve trauma symptoms and may in fact exacerbate them (Regehr, 2001). When applied to victims of trauma, however, the results raise more concerns. Mayou, Ehlers, and Hobbs (2000) randomly assigned traffic accident victims to a psychological debriefing group or a no-treatment group. At 4 months postinjury, the researchers reported that the psychological debriefing was ineffective, and at 3 years, the intervention group remained significantly more symptomatic compared with no treatment. They concluded that patients who initially had high intrusion and avoidance symptoms remained symptomatic if they received intervention but recovered if they did not receive intervention. Bisson, Jenkins, Alexander, and Bannister (1997) reported that burn victims who received debriefings had significantly higher rates of anxiety, depression, and PTSD 13 months following their injury compared with burn victims who did not receive debriefings. It has been suggested that the exposure elements of this group intervention are responsible for the iatrogenic effects in victims (Regehr, 2001).

Longer-term group models using CBT have more promising results. Foy and colleagues (2000) reviewed six studies of CBT group treatment with trauma survivors (three waitlist control and three single group pretestposttest) and indicated that all showed positive outcomes on PTSD symptom measures. Reported effect sizes ranged from 0.33 to 1.09 , with a mean of 0.68. Larger treatment effects were reported for avoidance symptoms than intrusion symptoms.

Thus, while trauma-resolution treatment approaches described in the literature are diverse, there is evidence that cognitivebehavioral methods are effective in symptom reduction. Several different models of CBT exist, some focusing on cognitive restructuring, some on symptom management, and some on exposure to traumatic imagery followed by anxiety management. As evidence suggests that each method may be effective, the concern that exposure therapy may increase distress and increase treatment dropout in high-risk groups suggests that this method should be used with caution. Pharmacological treatment for individuals with extremely high levels of distress should also be considered.

\section{Summary of Trauma Treatment Research}

- Good evidence exists that individual CBT treatment reduces trauma symptoms.

- Single-session groups may exacerbate symptoms.

- Exposure treatment, while effective with 
treatment completers, may require screening out of individuals with high anxiety, suicidal ideation, or other concurrent life crises.

\section{Toward an Empirically Based Model for Treating Traumatic Grief}

In reviewing existing studies on traumatic grief, it is difficult to differentiate those who have complicated grief due to relational issues with the lost loved one from those who lost an individual in a traumatic manner such as in a natural disaster or by murder, accident, or suicide. Based on our conceptual model of the co-occurrence of trauma and loss, we have included the few studies that evaluated treatment of individuals experiencing both in this section. As with grief and trauma, we must be cautious not to assume that all those who are confronted with traumatic loss will require intervention. For instance, despite a common belief that losing a family member to homicide is highly traumatizing, one study (Freedy, Resnick, Kilpatrick, Dansky, \& Tidwell, 1994) found that only $16 \%$ of those who had experienced such an event sought treatment. While it may be tempting to attribute this absence of treatment seeking to negative causes such as denial or avoidance, this finding may also reinforce the notion that individuals have a remarkable capacity to deal with the aftermath of tragedy.

Four studies utilized confrontation and exposure techniques for traumatic or complicated grief. Both Mawson, Marks, Ramm, and Stern (1981) and Sireling, Cohen, and Marks (1988) studied an intervention of guided mourning for bereaved individuals who were identified as having experienced chronic grief for at least 1 year. The behavioral intervention involved exposure to feared and avoided bereavement cues. The control group was instructed to avoid painful memories and fearful bereavement cues. In both studies, individuals in the intervention group improved more than those in the control condition; however, both groups improved. Mawson and colleague's 6 participants specifically improved in phobic symptoms and phobic distress and on the Texas Grief Inventory. Sireling, Cohen, and Marks's 26 participants had a significant improvement in cue avoidance, avoidance distress, and somatic symptoms compared with the antiexposure group. However, both the exposure treatment group and the group instructed to avoid triggers improved on the Texas Grief Inventory and measures of anxiety, depression, work functioning, and social functioning, lending some support to the notion that both grief confrontation and grief avoidance can lead to grief resolution (or that symptoms remit regardless of intervention). Brom, Kleber, and Defares (1989) evaluated a treatment intervention for individuals with loss-related instrusions, denial, avoidance, anxiety, sleeplessness, and guilt. Individuals were randomly assigned to a wait-list control; a trauma desensitization intervention, in which they were helped to relax and then confront their grief; a hypnosis therapy intervention, in which they were hypnotized and then encouraged to confront their grief; and a psychodynamic intervention, in which the therapist focused on discovering and solving psychological conflicts related to loss. Compared with the control, all three treatment groups had fewer symptoms as measured by the Impact of Events Scale; however, these results were not statistically significant. Individuals in intervention and control groups did not differ on somatization, social inadequacy, anger, trauma symptoms, or hostility. Shear et al. (2001) report the results of a treatment protocol involving exposure and interpersonal therapy with 21 people experiencing traumatic grief. While those who 
completed treatment had significantly lower levels of anxiety and depression than the control group, of note was that the 8 individuals who did not complete treatment were more likely to be grieving violent deaths by accidents, murder, or suicide, suggesting that these individuals may not have been able to tolerate treatment. Thus, it is not clear that exposure treatment is superior to avoidance or no treatment in individuals with complex or traumatic grief. Further, those in the Shear et al. study who had the most traumatic forms of loss did not complete treatment, perhaps because exposure was too anxiety provoking.

Murphy and colleagues (1998) studied the effects on parents who had recently lost a child to homicide, suicide, or accident. Identified as a high-risk group, these parents were randomly assigned to a combined emotion-focused and problem-focused group or a no-treatment control. Of note was the trend that mothers starting the intervention with high amounts of grief symptomatology and high levels of distress improved more in the intervention group than control. Conversely, those experiencing low symptomatology were worse off in the intervention than those in the control group, suggesting again that for those with normal grieving, intervention may in fact be iatrogenic. Fathers did not show long-term improvements from the intervention.

\section{Summary of Treatment for Traumatic Grief}

- Not all people with traumatic loss require treatment.

- Those with unresolved relationship issues toward the deceased may benefit from relationally based therapy.

- CBT aimed at cognitive restructuring and symptom management appears to be effective.

- Those with traumatic loss may experience increased distress in exposure therapy.

\section{Conclusions}

In summary, two divergent areas of study have focused on the experiences of bereavement and grief and on trauma and its aftermath. Beginning with the treatment efficacy literature in grief, several important issues emerge. First, there is little empirical evidence to suggest that individuals must work through their loss by expressing negative emotions and evaluating their relationship with the deceased. In particular, sharing these experiences with others in a group-treatment format does not appear to relieve symptoms of distress. Of note is that those who are experiencing normal grief (that is, grief that does not interfere with social, physical, or emotional functioning for prolonged periods of time) seem to not benefit from treatment. However, those with more complex forms of grief do appear to benefit from some individual models focused on relational components.

From the trauma treatment efficacy research, there is evidence that individually focused cognitive behavioral methods do lead to symptom reduction. There is some cause for caution surrounding exposure treatment methods, however. While exposure treatment has demonstrated efficacy when used appropriately, it may result in iatrogenic effects for those who are highly distressed or have concurrent challenges. These iatrogenic effects may be particularly problematic in single-session groups. Pharmacological treatments can be of benefit when symptoms of distress are overwhelming.

Integrating the findings from grief and trauma, it is first necessary to acknowledge the spontaneous remission of symptoms expe- 
rienced by both those individuals suffering from grief and those suffering the aftereffects of trauma. This speaks to the strength and resilience within individuals for managing distress and the importance of natural support mechanisms. Combined with evidence that some individuals not only do not benefit from treatment but in fact experience increased distress, we must be cautious about inferring that treatment is necessary for all individuals encountering traumatic loss. Frances, Clarkin, and Perry (1984) suggest that no treatment should be recommended when (1) no response to treatment can be expected or (2) there is a risk that the patient will have a negative response to treatment. While therapists may find it difficult to acknowledge the limitations and risks of treatment and accept that treatment may not benefit some extremely distressed and needy patients, no treatment may at times be the most responsible course of action. This avoids the pretense of therapy when no beneficial therapy exists, protects patients from iatrogenic harm, and allows patients to discover their own strengths and capabilities (Frances, Clarkin, \& Perry, 1984).

That being said, there is evidence that when individuals are suffering from traumatic grief and seek assistance for distress, treatment approaches can be of assistance. Depending upon the nature of the distress, a combination of relational therapy aimed at resolving relational ambivalence and developing a new sense of self and cognitive-behavioral approaches aimed at reducing symptoms of intrusion, anxiety, and avoidance have demonstrated effects and are least likely to result in iatrogenic effects.

\section{References}

American Psychiatric Association. (1980). Diagnostic and statistical manual of mental disorders (3rd ed.). Washington, DC: Author.
American Psychiatric Association. (2002). Diagnostic and statistical manual of mental disorders (4th ed., revised). Washington, DC: Author.

Albucher, R., \& Liberzon, I. (2002).

Psychopharmacological treatment in PTSD: A critical review. Journal of Psychiatric Research, 36, 355-367.

Archer, J. (1999). The nature of grief: The evolution and psychology of reactions to loss. London: Routledge.

Armour, M. (2002). Experiences of covictims of homicide: Implications for research and practice. Trauma, Violence, and Abuse, 3, 109-124.

Barrett, C. J. (1978). Effectiveness of widows' groups in facilitating change. Journal of Consulting and Clinical Psychology, 46, 20-31.

Bisson, J., Jenkins, P., Alexander, J., \& Bannister, C. (1997). Randomized controlled trial of psychological debriefing for victims of acute burn trauma. British Journal of Psychiatry, 171, 78-81.

Bleich, A., Gelkopf, M., \& Solomon, Z. (2003). Exposure to terrorism, stress-related mental health symptoms, and coping behaviors among a nationally representative sample in Israel. Journal of the American Medical Association, 290, 612-620.

Boelen, P., van den Bout, J., \& de Keijser, J. (2003). Traumatic grief as a disorder distinct from bereavement-related depression and anxiety: A replication study with bereaved mental health care patients. American Journal of Psychiatry, 160, 1339-1341.

Bonanno, G., \& Field, N. (2001). Examining the delayed grief hypothesis across 5 years of bereavement. American Behavioral Scientist, 44, 798-816.

Bowlby, J. (1980). Attachment and loss (Vol. 3). New York: Basic Books.

Brewin, C. (2001). A cognitive neuroscience account of posttraumatic stress disorder and its treatment. Behavior Research and Therapy, 39, 373-393.

Brewin, C. R., Andrews, B., \& Valentine, J. D. (2000). Meta-analysis of risk factors for 
posttraumatic stress disorder in trauma-exposed adults. Journal of Consulting and Clinical Psychology, 68, 748-766.

Briere, J., \& Elliott, D. (2000). Prevalence, characteristics, and long-term sequelae of natural disaster exposure in the general population. Journal of Traumatic Stress, 13, 661-679.

Brom, D., \& Kleber, R. (2000). On coping with trauma and coping with grief: Similarities and differences. In R. Malkinson, S. Rubin, \& E. Witztum (Eds.), Traumatic loss and nontraumatic loss and bereavement: Clinical theory and practice. Madison, CT: Psychosocial Press.

Brom, D., Kleber, R. J., \& Defares, P. (1989). Brief psychotherapy for posttraumatic stress disorders: A controlled outcome study. Journal of Consulting and Clinical Psychology, 57, 607-612.

Bryant, R., Sackville, T. Dang, S., Moulds, M., \& Guthrie, R. (1999). Treating acute stress disorder: An evaluation of cognitive behavior therapy and supportive counseling techniques. American Journal of Psychiatry, 156, 1780-1786.

Burgess, A., \& Holstrum, L. (1974). Rape trauma syndrome. American Journal of Psychiatry, 131, 981-986.

Calhoun, K., \& Atkeson, B. (1991). Treatment of rape victims: Facilitating psychosocial adjustment. Toronto: Pergamon Press.

Cohen, L., \& Roth, S. (1987). The psychological aftermath of rape: Long-term effects and individual differences in recovery. Journal of Social and Clinical Psychology, 5, 525-534.

Constantino, R. E. (1988). Comparison of two group interventions for the bereaved. Image: Journal of Nursing Scholarship, 20, 83-87.

DaCosta, J. (1871). On the irritable heart: A clinical study of a form of functional cardiac disorder following natural disaster. American Journal of Medical Sciences, 61, 17-52.

Duran, A. C. (1987). A grief intervention for adults experiencing conjugal bereavement. Unpublished doctoral dissertation, University of Utah.

Ehlers, A., \& Clark, D. (2003). Early psychological interventions for adult survivors of trauma: A review. Biological Psychiatry, 53, 817-826.
Eisenman, D., Gelberg, L., Liu, H., \& Shapiro, M. (2003). Mental health and health-related quality of life among adult Latino primary care patients living in the United States with previous exposure to political violence. Journal of the American Medical Association, 290, 627-634.

Field, N. P., Nichols, C., Holen, A., \& Horowitz, M. J. (1999). The relation of continuing attachment to adjustment in conjugal bereavement. Journal of Consulting and Clinical Psychology, 67, 212-218.

Finkbeiner, A. (1996). After the death of a child: Living with loss through the years. New York: Free Press.

Follette, V., Ruzek, J., \& Abueg, F. (1998). Cognitive-behavioral therapies for trauma. New York: Guilford Press.

Foy, D., Glynn, S., Schnurr, P., Jankowski, M., Wattenberg, M., Weiss, D., et al. (2000). Group therapy. In E. Foa, T. Keane, \& M. Friedman (Eds.), Effective treatments for PTSD: Practice guidelines for the International Society for Traumatic Stress Studies (pp. 155-175). New York: Guilford Press.

Frances, A., Clarkin, J., \& Perry, S. (1984). Differential therapeutics in psychiatry: The art and science of treatment selection. New York: Brunner/Mazel Publishers.

Freedy, J., Resnick, H., Kilpatrick, D., Dansky, B., \& Tidwell, R. (1994). The psychological adjustment of recent crime victims in the criminal justice system. Journal of Interpersonal Violence, 9, 450-468.

Freud, S. (1917). Mourning and melancholia: Standard edition of the complete psychological works of Sigmund Freud. London: Hogarth Press. Gerber, I., Wiener, A., Battin, D., \& Arkin, A. (1975). Brief therapy to the aged bereaved. In B. Schoenberg, A. Carr, A. Kutscher, D. Peretz, \& I. Goldberg (Eds.), Bereavement: Its psychosocial aspects (pp. 310-333). New York: Columbia University Press.

Gleser, G., Green, B., \& Winget, C. (1981). Prolonged psychosocial effects of disaster: A study of Buffalo Creek. New York: Academic Press.

Green, B. (2000). Traumatic loss: Conceptual and empirical links between trauma and 
bereavement. Journal of Personal and

Interpersonal Loss, 5, 1-17.

Green, B., Grace, M., \& Gleser, G. (1985). Identifying survivors at risk: Long-term impairment following the Beverly Hills Supper Club fire. Journal of Consulting and Clinical Psychology, 53, 672-678.

Green, B., Krupnick, J., Stockton, P., Goodman, L., Corcoran, C., \& Petty, R. (2001). Psychological outcomes associated with traumatic loss in a sample of young women. American Behavioral Scientist, 44, 817-837.

Harvey, A., Bryant, R., \& Tarrier, N. (2003). Cognitive behaviour therapy for posttraumatic stress disorder. Clinical Psychology Review, 23, 501-522.

Hembree, E., \& Foa, E. (2003). Interventions for trauma-related emotional disturbances in adult victims of crime. Journal of Traumatic Stress, 16, 187-199.

Hobfoll, S. E. (2001). The influence of culture, community, and the nested-self in the stress process: Advancing conservation of resources theory. Applied Psychology: An International Review, 50, 337-370; commentaries and rejoinder, 370-421.

Horowitz, M. (1976). Stress response syndromes. New York: Jason Aronson.

Horowitz, M., Siegel, B., Holen, A., Bonanno, G., Milbrath, C., \& Stinson, C. (1997). Diagnostic criteria for complicated grief disorder. American Journal of Psychiatry, 154, 904-910.

Humphrey, G. M., \& Zimpfer, D. G. (1996). Counselling for grief and bereavement. London: Sage Publications.

Jordan, J. R., \& Neimeyer, R. A. (2003). Does grief counseling work? Death Studies, 27, 765-786.

Kaltman, S., \& Bonanno, G. (2003). Trauma and bereavement: Examining the impact of sudden and violent deaths. Anxiety Disorders, 17, 131-147.

Kato, P. M., \& Mann, T. (1999). A synthesis of psychological interventions for the bereaved. Clinical Psychology Review, 19, 275-296.

Katz, D., Pellegrino, L., Pandya, A., Ng, A., \& DeLisis, L. (2002). Research on psychiatric outcomes and interventions subsequent to disasters: A review of the literature. Psychiatry Research, 110, 201-217.

Kessler, R., Sonnega, A., Bromet, E., Hughes, M., \& Nelson, C. (1995). Posttraumatic stress disorder in the National Comorbidity Study. Archives of General Psychiatry, 52, 1048-1060.

Kilpatrick, D., Resick, P., \& Veronen, L. (1981). Effects of a rape experience: A longitudinal study. Journal of Social Issues, 37, 105-122.

Lepore, S. J., Silver, R. C., Wortman, C. B., \& Wayment, H. A. (1996). Social constraints, intrusive thoughts, and depressive symptoms among bereaved mothers. Journal of Personality and Social Psychology, 70, 271-282.

Lindemann, E. (1944). Symptomatology and management of acute grief. American Journal of Psychiatry, 101, 141-148.

Litterer Allumbaugh, D., \& Hoyt, W. T. (1999). Effectiveness of grief therapy: A meta-analysis. Journal of Counseling Psychology, 46, 370-380.

MacKenzie, J. (1916). The soldier's heart and war neurosis: A study in symptomology. British Medical Journal, 1, 491-495.

Mawson, D., Marks, I. M., Ramm, L., \& Stern, R. S. (1981). Guided mourning for morbid grief: A controlled study. British Journal of Psychiatry, 138, 185-193.

Mayou, R., Ehlers, A., \& Hobbs, M. (2000). Psychological debriefing for road traffic accident victims. British Journal of Psychiatry, 176, 589-593.

McCann, L., Sakheim, D., \& Abrahamson, D. (1988). Trauma and victimization: A model of psychological adaptation. The Counseling Psychologist, 16, 531-594.

Middleton, W., Burnett, P., Raphael, B., \& Martinek, N. (1996). The bereavement response: A cluster analysis. British Journal of Psychiatry, $169,167-171$.

Mott, F. (1918). War psychoneurosis. Neurasthenia: The disorders and disabilities of fear. Lancet, 1, 127-129.

Murphy, S. A., Johnson, C., Cain, K. C., Das Gupta, A., Dimond, M., Lohan, J., et al. (1998). Bond spectrum group treatment for parents bereaved by the violent deaths of their 12- to 28year-old children. Death Studies, 22, 209-236. 
Najarian, L., Goenjian, A., Pelcovitz, D., Mandel, F., \& Najarian, B. (2001). The effect of relocation after a natural disaster. Journal of Traumatic Stress, 14, 511-526.

Neimeyer, R. A. (2000). Searching for the meaning of meaning: Grief therapy and the process of reconstruction. Death Studies, 24, 541-558.

Norris, F. H., Friedman, M. J., \& Watson, P. J. (2002). 60,000 disaster victims speak: Part II. Summary and implications of the disaster mental health research. Psychiatry, 65, 240-260.

Ogrodniczuk, J. S., Piper, W. A., McCallum, M., Joyce, A. S., \& Rosie, J. S. (2002). Interpersonal predictors of group therapy outcome for complicated grief. International Journal of Group Psychotherapy, 52, 511-535.

Oppenheimer, B., \& Rothschild, M. (1918). The psychoneurotic factor in the "irritable heart of soldiers." British Medical Journal, 2, 29-31.

Page, H. (1885). Injury of the spinal cord without apparent lesion and nervous shock, in their surgical and medico-legal aspects. London: J \& A Church.

Parkes, C. M. (1996). Bereavement: Studies of grief in adult life. Harmondsworth, UK: Pelican.

Pfefferbaum, B., Call, J., Lensgraf, S., Miller, P., Flynn, B., Doughty, D., et al. (2001). Traumatic grief in a convenience sample of victims seeking support services after a terrorist incident. Annals of Clinical Psychiatry, 13, 19-24.

Piper, W. E., McCallum, M., Joyce, A. S., Rosie, J. S., \& Ogrodniczuk, J. S. (2001). Patient personality and time-limited group psychotherapy for complicated grief. International Journal of Group Psychotherapy, 51, 525-552.

Prigerson, H., Bridge, J., Maciejewski, P., Beery, L., Rosenheck, R., Jacobs, S., et al. (1999). Influence of traumatic grief on suicidal ideation among young adults. American Journal of Psychiatry, 156, 1994-1995.

Prigerson, H., Shear, M., Jacobs, S., Reynolds, C., Maciejewski, P., Davidson, J., et al. (1999). Consensus criteria for traumatic grief: A preliminary empirical test. British Journal of Psychiatry, 174, 67-73.

Rando, T. A. (1992). The increasing prevalence of complicated mourning: The onslaught is just beginning. Omega: Journal of Death and Dying, 26, 43-59.

Raphael, B. (1977). Preventive intervention with the recently bereaved. Archives of General Psychiatry, 34, 1450-1454.

Raphael, B. (1997). The interaction of trauma and grief. In D. Black, M. Newman, J. HarrisHendriks, \& G. Mezey (Eds.), Psychological trauma: A developmental approach. London: Gaskell.

Regehr, C. (2001). Crisis debriefings for emergency responders: Reviewing the evidence. Brief Treatment and Crisis Intervention, 1, 87-100.

Roberts, A. R. (2002). Assessment, crisis intervention, and trauma treatment: The integrative ACT intervention model. Brief Treatment and Crisis Intervention, 2, 1-21.

Roberts, A., \& Yeager, K. (Eds.). (2004). Handbook of practice-focused research and evaluation. New York: Oxford University Press.

Rock, P. (1998). After homicide: Practical and political responses to bereavement. New York: Oxford University Press.

Rosen, A., Proctor, E., \& Staudt, M. (2003). Targets of change and interventions in social work: An empirically based prototype for developing practice guidelines. Research on Social Work Practice, 13, 208-233.

Rothbaum, B., \& Foa, E. (1996). Cognitivebehavioral therapy for posttraumatic stress disorder. In B. van der Kolk, A. McFarlane, \& L. Weisaeth (Eds.), Traumatic stress: The effects of overwhelming experience on mind, body, and society (pp. 491-510). New York: Guilford Press. Rothbaum, B., Foa, E., Riggs, D., Murdock, T., \& Walsh, W. (1992). A prospective examination of posttraumatic stress disorder in rape victims. Journal of Traumatic Stress, 60, 748-756.

Sabatini, L., (1988). Evaluating a treatment program for newly widowed people. Omega, 19, 229-236.

Sackett, D., Richardson, W., Rosenberg, W., \& Haynes, R. (1997). Evidence-based medicine: How to practice and teach EBM. New York: Churchill Livingstone.

Sanders, C. M. (1993). Risk factors in bereavement outcome. In M. S. Stroebe, W. Stroebe, \& R. O. 
Hansson (Eds.), Handbook of bereavement:

Theory, research, and intervention (pp. 255-267).

New York: Cambridge University Press.

Schut, H. A., Stroebe, M. S., van den Bout, J., \& Terheggen, M. (2001). The efficacy of bereavement interventions. Determining who benefits. In M. S. Stroebe, W. Stroebe, \& R. O. Hansson (Eds.), Handbook of bereavement: Theory, research, and intervention (pp. 705-737). New York: Cambridge University Press.

Shalev, A. (2002). Acute stress reactions in adults. Society of Biological Psychiatry, 51, 532-543.

Shear, M., Frank, E., Foa, E., Cherry, C., Reynolds, C., Vander Bilt, J., et al. (2001). Traumatic grief: A pilot study. American Journal of Psychiatry, 158, 1506-1508.

Shuchter, S. R., \& Zisook, S. (1993). The course of normal grief. In M. S. Stroebe, W. Stroebe, \& R. O. Hansson (Eds.), Handbook of bereavement: Theory, research, and intervention (pp. 23-43). New York: Cambridge University Press.

Sireling, L., Cohen, D., \& Marks, I. (1988). Guided mourning for morbid grief: A controlled replication. Behavior Therapy, 19, 121-132.

Solomon, S., \& Johnson, D. (2002). Psychosocial treatment of posttraumatic stress disorder: A practice-friendly review of outcome research. Psychotherapy in Practice, 58, 947-959.

Southward, E. (1919). Shell shock. Boston: W. M. Leonard.

Stroebe, M. S. (1992). Coping with bereavement: A review of the grief work hypothesis. Omega: Journal of Death and Dying, 26, 19-42.

Stroebe, M. S., \& Schut, H. (1999). The dual process model of coping with bereavement: Rationale and description. Death Studies, 23, 197-224.

Stroebe, M., Schut, H., \& Finkenauer, C. (2001). The traumatization of grief? A conceptual framework for understanding the traumabereavement interface. Israeli Journal of Psychiatry-Related Sciences, 38, 185-201.

Stroebe, W., \& Stroebe, M. (1991). Does "grief work" work? Journal of Consulting and Clinical Psychology, 59, 479-482.

Stroebe, W., \& Stroebe, M. (1993). Determinants of adjustment to bereavement in younger widows and widowers. In M. S. Stroebe, W. Stroebe, \& R. O. Hansson (Eds.), Handbook of bereavement: Theory, research, and intervention (pp. 208-226). New York: Cambridge University Press.

Tarrier, N., Pilgrim, H., Sommerfield, C., Faragher, B., Reynolds, M., Graham, E., et al. (1999). A randomized trial of cognitive therapy and imaginal exposure in the treatment of chronic posttraumatic stress disorder. Journal of Consulting and Clinical Psychology, 67, 13-18.

Tarrier, N., Sommerfield, C., Reynolds, M., \& Pilgrim, H. (1999). Symptom self-monitoring in the treatment of posttraumatic stress disorder. Behaviour Therapy, 30, 597-605.

Thompson, M., Norris, F., \& Ruback, R. (1998). Comparative distress levels of inner-city family members of homicide victims. Journal of Traumatic Stress, 11, 223-242.

Tudiver, F., Hilditch, J., Permaul, J. A., \& McKendree, D. J. (1992). Does mutual health facilitate newly bereaved widowers? Evaluation and the Health Professions, 15, 147-162.

Turnbull, G. (1998). A review of post-traumatic stress disorder. Part 1: Historical development and classification. Injury, 29, 87-91.

Vachon, M. L. S., Lyall, W. A. L., Rogers, J., Freedman-Letofsky, K., \& Freeman, S. J. J. (1980). A controlled study of self-help intervention for widows. American Journal of Psychiatry, 137, 1380-1384.

van der Kolk, B. (1997). The psychobiology of posttraumatic stress disorder. Journal of Clinical Psychiatry, 58, 16-24.

van der Kolk, B., \& van der Hart, O. (1989). Pierre Janet and the breakdown of adaptation in psychological trauma. American Journal of Psychiatry, 146, 1530-1540.

Walls, N., \& Meyers, A. W. (1985). Outcome in group treatments for bereavement: Experimental results and recommendations for clinical practice. International Journal of Mental Health, 13, 126-147.

Weidaw, C. J. (1987). The effects of attending a bereavement support seminar on level of depression of bereaved spouses within the first year 
after the spouses' deaths: An experimental study. Unpublished doctoral dissertation, Western Michigan University.

Weiss, R. S. (2001). Grief, bonds, and relationships. In M. S. Stroebe, R. O. Hansson, W. Stroebe, \& H. Schut (Eds.), Handbook of bereavement research: Consequences, coping, and care (pp. 47-62). Washington, DC: American Psychological Association.
Worden, J. W. (1991). Grief counseling and grief therapy: A handbook for the mental health practitioner. New York: Springer Publishing Co. Yehuda, R. (1998). Psychoneuroendocrinology of posttraumatic stress disorder. Psychiatric Clinics of North America, 21, 359-379.

Yehuda, R. (2002). Clinical relevance of biologic findings in PTSD. Psychiatric Quarterly, 73, 123-133. 